\title{
Advances in Exosome-Based Drug Delivery and Tumor Targeting: From Tissue Distribution to Intracellular Fate
}

This article was published in the following Dove Press journal: International Journal of Nanomedicine

\author{
Juntang Shao ${ }^{1,2}$ \\ Jennica Zaro ${ }^{3}$ \\ Yuxian Shen $\mathbb{D}^{1,2}$ \\ 'Department of Pharmacology, Anhui \\ Medical University School of Basic \\ Medicine, Hefei 230032, People's \\ Republic of China; ${ }^{2}$ Biopharmaceutical \\ Research Institute, Anhui Medical \\ University, Hefei, People's Republic of \\ China; ${ }^{3}$ Department of Pharmacology \\ and Pharmaceutical Sciences, University \\ of Southern California School of \\ Pharmacy, Los Angeles, CA 90089 - \\ 9121, USA
}

\begin{abstract}
Exosomes or small extracellular vesicles are considered a new generation of bioinspired-nanoscale drug delivery system (DDS). Endogenous exosomes function as signalosomes since they convey signals via ligands or adhesion molecules located on the exosomal membrane, or packaged inside the exosome. Recently, exosome membrane modification, therapeutic payloads encapsulation, and modulation of in vivo disposition of exosomes have been extensively investigated, among which significant advances have been made to optimize exosome-mediated delivery to solid tumors. Exosomes, specifically tumor cell-derived exosomes, are presumed to have tumor-preferential delivery due to the homotypic features. However, quality attributes that dictate the tissue distribution, cell typeselective uptake, and intracellular payload release of the administered exosomes, as well as the spatiotemporal information regarding exosome fate in vivo, remain to be further investigated. This review summarizes recent advances in developing exosomes as drug delivery platforms with a focus on tumor targeting. The pharmacokinetic features of naive exosomes and factors influencing their intracellular fate are summarized. Recent strategies to improve tumor targeting of exosomes are also reviewed in the context of the biological features of tumor and tumor microenvironment (TME). Selected approaches to augment tumor tissue deposition of exosomes, as well as methods to enhance intracellular payload delivery, are summarized with emphasis on the underlying mechanisms (eg, passive or active targeting, endosomal escape, etc.). In conclusion, this review highlights recently reported tumortargeting strategies of exosome-based drug delivery, and it's in the hope that multiple approaches might be employed in a synergistic combination in the development of exosomebased cancer therapy.
\end{abstract}

Keywords: exosome, tumor-targeting, PK, drug delivery, nanovesicles

\section{Introduction}

Extracellular vesicles (EVs) are lipid bilayer-enclosed membranous structures secreted by cells under physiological conditions or following biological cues. ${ }^{1}$ EVs comprise heterogenous populations with various sizes and subcellular origin of membranes. Since a consensus regarding specific markers of EV subtypes has not emerged, the term "exosome" in this review refers to small EVs with a size range of 40-160 nm with putative membrane origin from endosomal pathways. ${ }^{2}$ Exosomes are initially formed as intraluminal vesicles (ILV) in late endosomes through inward invagination. Subsequently, ILV form multivesicular bodies (MVB) through endosomal-sorting complexes required for transport (ESCRT)-dependent or
Correspondence: Yuxian Shen; Juntang Shao

Department of Pharmacology, Anhui Medical University School of Basic Medicine, 8I Meishan Road, Hefe 230032, People's Republic of China Tel +8665I6II33

Email shenyx@ahmu.edu.cn; shaojuntang@ahmu.edu.cn
International Journal of Nanomedicine 2020:15 9355-937I 
ESCRT-independent processes. ${ }^{3}$ The term "exosome" was coined in the 1980s in the first report that exosomes were secreted upon MVB fusion with the plasma membrane during reticulocyte maturation. ${ }^{4}$ Since then, the physiological functions of exosomes as well as their roles in disease progression have been appreciated. ${ }^{5}$ Exosomes permit contact-free substance exchange between cells and act as signaling vesicles in autocrine, endocrine, juxtracrine, paracrine, or distal modes of communication. ${ }^{6}$ It has been shown that exosomes are involved in various biological processes including viral infection, immune responses, mammalian development, and reproduction. ${ }^{7}$ Interestingly, exosomes may exert opposite functions depending on the producer cells and the biological context. For example, leukocyte-derived exosomes containing IFN $\alpha$ limit virus replication, whereas exosomes released by infected cells promote infection through exosomemediated viral transfer. ${ }^{8}$ The purpose of physiological secretion of exosomes and the mechanisms that compel their release remain largely unknown and require further in-depth investigation. On the other hand, research interests have extended to the value of exosomes in the diagnosis of cancer, degenerative and metabolic diseases, which are evaluated by many ongoing clinical investigations. ${ }^{9}$

Exosomes are also characterized as signalosomes since they convey signals via ligands or adhesion molecules expressed on the exosomal membrane, or packaged as cargo inside the exosome. ${ }^{10}$ Therefore, exosomes mediate signal transduction either by membranous interactions with the plasma membrane of recipient cells, or by payload release following cell uptake of exosomes. ${ }^{11}$ This exosomemediated communication has several unique features. First, exosomal membrane derived from MVB contains combinations of ligands that can simultaneously engage with multiple cell-surface receptors, providing a network of information in a way that highly simulates direct cell-cell contact. ${ }^{12}$ Second, binding of exosomes to recipient cells results in 'new' cell membrane bearing surface molecules from donor cells. Therefore, targeted cells acquire new properties of adhesion or cell recruitment. ${ }^{13}$ Third, exosomes provide an excellent platform for intracellular delivery of genes or proteins to reprogram targeted cells. For example, mesenchymal stem cell (MSC)-derived exosomes loaded with an anti-microRNA oligonucleotide can effectively silence the targeted microRNA in glioblastoma multiforme cells. ${ }^{14}$ By taking advantages of those aforementioned features, exosomes open up opportunities for the development of safer and more effective drug delivery tools. Compared with liposomes or other synthetic polymerbased drug carriers, exosomes contain transmembrane and membrane-anchored proteins that enhance endocytosis and therefore, promote payload delivery. ${ }^{15}$ Another advantage of exosomes is due to their bio-originated membrane, which is inert to protein corona formation. ${ }^{16}$ Moreover, there is ample flexibility in exosomal surface modification by genetic manipulation of donor cells to accommodate multiplexed purposes. For instance, exosomes derived from CD47overexpressed human foreskin fibroblasts have been shown to decrease phagocytosis-mediated clearance by monocytes and macrophages, as well as enhance cell uptake by cancer cells. ${ }^{17}$

This review summarizes recent advances in developing exosomes as drug delivery platforms with a focus on tumor targeting. Properties influencing PK of naive exosomes, as well as modifications to overcome tissue and cellular barriers for tumor targeting, are reviewed and summarized. In this review, modifications of exosomes to augment the enhanced permeability and retention (EPR) effect is reviewed in the passive targeting part. Strategies involve utilizing affinity ligands or targeting moieties on the surface of exosomes for tumor microenvironment (TME) normalization, increased retention at the tumor site, and uptake by the cancer cells are discussed in the active targeting section. The ligands are selected to bind to overexpressed proteins on cancer cell surfaces or to target specific cell populations in TME. The tissue-selective homing property of exosomes is influenced by the producing cells. Therefore, the other classification of active or passive targeting exosomes is according to whether the modification is by alteration of exosome-producing cells' transcriptome. ${ }^{18}$ As for exosome biogenesis, content, and functions under physiological or pathological conditions, readers are referred to excellent reviews for detailed information. ${ }^{19-21}$ In addition, technologies in cargo loading, surface modification, and up-scale manufacture of exosome have been comprehensively reviewed in previous publications. $^{22-25}$

\section{Exosomes and Exosome-Inspired Drug Delivery}

Great efforts have been invested to optimize exosomal membrane properties and to improve the manufacturing process of exosomes or exosome mimetics. Here we categorized exosome-based drug delivery tools into three 
subgroups according to the degree of human manipulation, ie, how "natural" they are compared with exosomes released from cells (Table 1). The most well-studied exosomes are isolated from cell culture conditioned medium. Common protein components found in exosomes include cytoskeletal (eg, actin), cytosolic (eg, GAPDH), heat shock (eg, HSP90), antigen presentation (MHC-I, -II), and membrane proteins (eg, CD9, CD63), as well as proteins involved in vesicle trafficking (eg, Tsg101). ${ }^{3}$ In addition, exosomes derived from different cell types may exhibit unique protein profiles, which are associated with intrinsic functions of donor cells and are also impacted by cell conditions. Therefore, the origins of producer cells will be summarized below in order to provide information about choosing the cell/cell lines to fulfil different study objectives. Furthermore, efforts in developing exosome mimetics to overcome technical obstacles, such as low loading efficiency or poor yield, are also discussed. On a supplementary note, milk- or plant-derived exosomes have shown potentials as drug carriers for oral delivery with minimal biosafety concerns. ${ }^{26,27}$

\section{Exosomes from Culture Conditioned Media}

Exosomes can be isolated from conditioned cell culture media using various methods, including sequential or gradient ultracentrifugation, filtration, polymer precipitation, size exclusion-chromatograph, and immunoaffinity capture. ${ }^{28}$ Various properties of exosomes are affected by the isolation method, including the yield, size distribution, surface charge, and protein content. However, standard operation procedures in exosome preparation, including isolation and purification, have not been established. Selection of one specific method or combination of

Table I Exosome-Based Delivery Vesicles and Features

\begin{tabular}{|c|c|c|c|}
\hline \multicolumn{2}{|c|}{ Cell-Secreted } & \multirow{2}{*}{\begin{tabular}{|l} 
Exosome Features \\
- induce potent cellular immune responses \\
- serve as cancer vaccine to boost NK cell activity in non-small cell lung cancer patient
\end{tabular}} & \multirow{2}{*}{$\begin{array}{l}\text { Ref. } \\
123\end{array}$} \\
\hline $\begin{array}{l}\text { Immune } \\
\text { cells }\end{array}$ & DCs & & \\
\hline & imDCs & $\begin{array}{l}\text { - contain miR-682 and promote immune tolerance via suppression of Rho-associated protein } \\
\text { kinase } \\
\text { - reduced immunogenicity as drug carrier }\end{array}$ & 124 \\
\hline & NK cells & $\begin{array}{l}\text { - contain killer proteins (granzyme and perforin) to exert cytotoxicity to tumor cells } \\
\text { - tumor-specific accumulation of NK-EXOs }\end{array}$ & 125 \\
\hline & $\begin{array}{l}\text { effector CAR-T } \\
\text { cells }\end{array}$ & $\begin{array}{l}\text { - express a high level of cytotoxic molecules and inhibit tumor growth } \\
\text { - do not express Programmed cell Death protein I (PDI) compared with CAR-T cells }\end{array}$ & 46 \\
\hline \multicolumn{2}{|c|}{ Cancer cells or cell lines } & - targeting homotypic tumors & 103 \\
\hline \multicolumn{2}{|l|}{ MCSs } & $\begin{array}{l}\text { - contain tissue regenerative growth factors for degenerative diseases } \\
\text { - allogeneic host to provide "off-the-shelf" cell-derived product }\end{array}$ & $\begin{array}{l}126 \\
127\end{array}$ \\
\hline \multicolumn{2}{|c|}{ HEK293T } & $\begin{array}{l}\text { - ideal host cell for membrane modification through genetic manipulation } \\
\text { - immune inert }\end{array}$ & 93 \\
\hline \multicolumn{2}{|c|}{ Exosome mimetics } & Exosome features & \\
\hline \multicolumn{2}{|c|}{ liposome-exosome hybrid } & $\begin{array}{l}\text { - increased exosome yield } \\
\text { - mitigate functional loss of cargo during loading }\end{array}$ & 128 \\
\hline \multicolumn{2}{|c|}{ Cell extrusion } & $\begin{array}{l}\text { - increased exosome yield } \\
\text { - exosome-mimetics from primary hepatocytes aid liver regeneration }\end{array}$ & 51,129 \\
\hline \multicolumn{2}{|c|}{ Food-derived } & Exosome features & \\
\hline \multicolumn{2}{|c|}{$\begin{array}{l}\text { milk } \\
\text { edible plants }\end{array}$} & $\begin{array}{l}\text { - cross gastrointestinal tract via the neonatal Fc receptor } \\
\text { - desirable nanoparticle morphology, environmentally safe and non-hazardous } \\
\text { - eminent potential for industrial pharmaceutical production }\end{array}$ & $\begin{array}{l}116 \\
130\end{array}$ \\
\hline
\end{tabular}

Abbreviations: DCs, dendritic cells; imDCs, immature dendritic cells; NK cells, natural killer cells; NK-EXOs, NK cell-derived exosomes; CAR-T cells, chimeric antigen receptor T cells; MCSs, mesenchymal stem cells. 
methods depends on the nature of the samples as well as the study objectives. Various different cell lines have been utilized for exosome isolation (Table 1). For example, Tian et al used mouse immature dendritic cells (imDCs) to produce exosomes with surface expression of iRGD peptide, which navigated exosomes towards $\alpha_{\mathrm{v}}$ integrin expressing cancer cells. ${ }^{29}$ ImDCs were chosen as the donor cells to reduce immunogenicity and toxicity of exosomes, considering that imDCs are immune tolerogenic cells with low ratios of co-stimulatory to inhibitory signal. ${ }^{30}$ On the other hand, exosomes released from antigen-pulsed DCs boost immune responses against cancer and might serve as a cell-free nanoscale vaccine in cancer immunotherapy. ${ }^{31}$ Natural killer (NK) cells have also been utilized to produce exosomes with antitumor effects, by means of the encapsulation of cellular perforin and granzymes during EV biogenesis. ${ }^{32,33}$ Apart from immune cells, MSCs are a popular candidate for EV production, and exosomes are considered as a vital venue for the secretion of trophic factors, by which MSCs aid tissue repair and regeneration. ${ }^{34}$ In vivo studies have demonstrated that MSCs-derived exosomes can facilitate spinal cord repair after injury, ${ }^{35}$ mitigate joint inflammation in osteoarthritis, ${ }^{36}$ and improve cardiac functions in ischemia-refusion injury. ${ }^{37}$ Moreover, MSCs possess large ex vivo expansion capacity and are immunosuppressive and, therefore, are compatible with mass production of exosomes for both autologous and allogenic clinical applications. $^{38}$

Human embryonic kidney (HEK293) cells have wide applications in biopharmaceutical manufacturing, and represent one of the few mammalian cell lines to produce therapeutic biologics accepted by FDA. ${ }^{39}$ In addition, HEK293 cells are amenable to various transfection methods and permit genetic manipulation to engineer the exosome surface or to load cargos during exosome biogenesis. ${ }^{40}$ Previous studies have also reported that exosomes generated from HEK293 are immunologically inert and do not trigger inflammatory responses in vivo. ${ }^{41}$

Cancer cell lines were presumed to be efficient exosome producers since cancer cells overexpressed Rab GTPases Rab27a and Rab27b, which promote exosome secretion by facilitating multivesicular endosome (MVE) docking at the plasma membrane. ${ }^{42}$ In addition, exosomes' tropism toward their cell origin could be utilized for cancer targeting. As exemplified in studies from Kim et al, ${ }^{43}$ ovarian cancer cell line SKOV3-derived exosomes displayed enhanced tumor accumulation in SKOV3 xenografted mice compared with HEK293-derived exosomes. However, there have been concerns about directly using tumor cell-produced naïve exosomes as drug carriers for several reasons. First of all, the pharmacokinetic profile of unmodified exosomes is less ideal in regards of their short plasma half-life and low targeting efficiency. Unmodified tumor exosomes exhibit a short half-life of less than 5 minutes after IV bolus in mice, and rapid clearance, which is partly due to complement opsonization in the innate immune system. ${ }^{44}$ Minimal tumor accumulation is observed as well, though intratumor-injected exosomes remain associated with tumors to a significantly greater extent compared with liposomes. In addition, cancer cells by nature release exosomes with surface expression of programmed death-ligand 1 (PD-L1), an important form of soluble PD-L1 that mediates immunosuppression to aid tumor growth. ${ }^{45}$ Therefore, measurement of exosomal PD-L1 expression is necessary before applying those unmodified exosomes as drug carriers, especially in combination with PD1- or PD-L1-blocking immunotherapy. ${ }^{46}$ In addition to membrane features of exosomes, the landscape of the encapsulated protein or gene materials is disparate. ${ }^{47}$ For example, miRNAs in exosomes derived from PC3 cells, but not from HEK293, can modulate the integrin pathway and induce macrophage M2 polarization. On the other hand, miRNAs in HEK293 exosomes are involved in cell migration through cadherin signaling. ${ }^{48}$ Therefore, the endogenous content within exosomes needs stringent investigation and risk-to-benefit assessment before choosing a cell line as the producer cell of exosomes for drug delivery.

\section{Exosome-Mimetics}

Naturally released exosomes inspire the development of exosome-mimetic nanovesicles (EMNVs). Even though exosome secretion is considered as highly efficient with a secretion rate of about 100 exosome particles/cell/hour based on single-cell assays, ${ }^{49}$ the yield of exosome isolation using culture conditioned is limited, with the commonly observed yield of $<0.1$ exosome particles/cell/ hour. ${ }^{50}$ One straightforward approach to overcome the issue for large-scale production is to generate EMNVs by serially extruding cells through micro-sized filters (Table 1). Using this method, the yield is boosted over 100-fold, while EMNVs keep the biological functions similar as naïve exosomes.

EMNVs derived from different cell lines have been used to treat various diseases. For example, EMNVs 
manufactured using primary hepatocytes promote liver regeneration in mice with partial hepatectomy $(\mathrm{PH}) .{ }^{51}$ Pancreatic $\beta$-cell-derived EMNVs induce bone marrow (BM) cells to differentiate into insulin-producing cells, serving as potential therapeutics for diabetes. ${ }^{52}$ In addition, payloads such as anticancer drug doxorubicin could be encapsulated simultaneously along with serial extrusion of cells to further improve treatment of cancer. ${ }^{53}$ However, EMNVs have mixed membrane components from both plasma membrane and intracellular organelles, whereas the exosome membrane is primarily originated from ILV in endosomal pathways. ${ }^{3}$ Additionally, certain lipid species, such as sphingolipids, cholesterol, and phospholipid phosphatidylserine, are more enriched in exosomes compared with that in their donor cells. ${ }^{54}$ Therefore, one open question is whether the altered membrane composition would impact in vivo PK/PD behavior of EMNVs compared with naive exosomes, especially after long-term application. This concern also applies to nanoparticles cloaked with plasma membrane. ${ }^{55}$

Exosome-liposome hybrid nanoparticles are developed to overcome the low encapsulation of large size nucleic acids, such as plasmid. Lin et $\mathrm{al}^{56}$ have used liposome as an intermittent carrier for Cas9 plasmids with a minimal size of 5-6 kb. Afterwards, liposome is incubated with exosomes to form hybrid NVs and enables plasmid loading by vesicles fusion. However, hybrid exosomes display cytotoxicity similar as liposomes (Lipofectamine) and, therefore, they should be further investigated using liposomes with less toxicity.

\section{Pharmacokinetic Characteristics and Tumor Distribution of Naive Exosomes}

Tissue distribution of exosomes, similar to other nanovesicles, is dictated by particle size, surface charge, and the composition of lipid bilayers. ${ }^{57}$ Quantitative distribution studies using radioactive tracers have shown that the majority of unmodified exosomes is distributed to the liver, lung, and spleen after IV administration. ${ }^{58}$ Clearance of exosome is primarily mediated by the mononuclear phagocyte system (MPS). ${ }^{59}$ Exosomes carry a slightly negative charge on the surface, and are expected to reduce MPS-mediated clearance compared with positively-charged NPs. ${ }^{60}$ However, phosphatidylserine, a negatively charged lipid, is involved in macrophage uptake of exosomes as part of exosome clearance. ${ }^{61}$ On the other hand, surface expression of glycosylphosphatidylinositol (GPI)-anchored CD55 and CD59 have been shown to protect exosomes from complement-mediated lysis. ${ }^{62}$ On a special note, endogenous exosomes present in blood circulation also impact the in vivo fate of administered exosomes. For instance, a pre-IV injection of peripheral blood-derived exosomes reduces the hepatic accumulation of subsequently injected grapefruit-derived exosomes. Furthermore, tissue distribution of grapefruit-derived exosomes is redirected to the lung and tumor. In the study, endogenous exosomes inhibited macrophage uptake of exogenous exosomes by activating the CD36-mediated pathway, therefore serving as a competitor in hepatic clearance of exosomes. ${ }^{63}$ In addition to the circulated level of endogenous exosomes, the doses of administered exosomes could also alter the tissue distribution. It has been observed that increasing the dose level of exosome (400 $\mu \mathrm{g}$ ) leads to massive lung deposition, while a lower dose of exosome $(60 \mu \mathrm{g})$ is predominantly distributed to the liver and spleen. ${ }^{44}$

As for tumoral distribution, exosomes falling within the size range of 100-200 $\mathrm{nm}$ are anticipated to exhibit the enhanced permeability and retention (EPR effect) in tumors. ${ }^{64}$ Moreover, exosomes are well known for their homotropic feature, therefore offering an additional mechanism to enable tumor targeting when utilizing tumor cell generated exosomes as delivery vectors. The expression pattern of integrin has been shown as one determining factor in exosome organotropism. For example, exosomal integrins $\alpha_{6} \beta_{4}$ and $\alpha_{6}$ $\beta_{1}$ were associated with lung metastasis, while exosomal integrin $\alpha_{\mathrm{v}} \beta_{5}$ was linked to liver metastasis. ${ }^{65}$ In addition, glycans exposed on exosomes also impact their tissue distribution as well as cell targeting. For example, glycosaminoglycans exposed on glioblastoma exosomes direct the targeting of exosomes to CCR8positive glioblastoma cells via a triple interaction with CCR8 ligand CCL18 as the bridging molecule. ${ }^{66}$ The mildly acidic $\mathrm{pH}$ in the tumor microenvironment (TME) also boosts exosome uptake by cancer cells. This targeting effect is attributed to high levels of sphingomyelin/ganglioside GM3 ( $\mathrm{N}$-acetyl neuraminylgalactosyl glucosylceramide) in the exosomal membrane. GM3 becomes positively charged in a rich acidic environment, resulting in better exosome-cell fusion than that at physiological $\mathrm{pH} 7.4 .^{67}$ 


\section{Strategies to Improve Tumor Targeting of Exosome}

The homotypic targeting of tumor cell-derived exosomes has been demonstrated using in vitro accumulation studies. ${ }^{68}$ However, the tumor targeting shows discrepancies in vivo across studies. Qiao et $\mathrm{al}^{69}$ reported that HT1080 cell-derived exosomes homed to their origin cells, resulting in enhanced tumor accumulation in HT1080 cell-xenografted mice compared with HeLaderived exosomes. On the other hand, Smyth et $\mathrm{al}^{44}$ found that exosomes released by $4 \mathrm{~T} 1, \mathrm{MCF}-7$, and PC3 cells displayed minimal tumor accumulation after IV injection, which may be partly due to the rapid blood clearance. In vivo blockade of scavenger receptor-A (SR-A) with dextran sulfate dramatically decreased monocytes/macrophage-mediated hepatic clearance of exosomes in mice and, therefore, enhanced tumor accumulation of exosomes by 5 -fold. ${ }^{70}$ Those results suggest that optimization of exosomes is necessary to achieve efficient tumor targeting. The following sections focuses on strategies to improve tumor targeting of exosome-based delivery vectors, where passive or active targeting mechanisms are discussed separately (Figure 1).

\section{Boosting EPR in Passive Tumor Targeting}

Passive tumor targeting of nanoparticles (NPs) is a result of the EPR effect, described as the increased permeability of tumor vasculature and ineffective lymphatic drainage. However, only a small fraction (less than $1 \%$ ) of NPs accumulate even in high-EPR xenografted tumors. ${ }^{71}$ The targeting efficiency of NPs is compromised due to uneven permeability of the heterogeneous size of endothelial gaps, dense interstitial tumor matrix, and inadequate blood perfusion. ${ }^{72}$ In addition, studies indicated that actively targeted NPs must first reach the target to take advantage of this increased affinity and avidity to cancer cells. ${ }^{73}$ Efficient passive targeting is considered a prerequisite for systemically administered NPs designed to target tumor specificcells. Approaches to enhance EPR includes prolonging the circulation time of NPs as well as boosting their extravasation. ${ }^{74}$ Exosomes are primarily cleared via phagocytosis and endocytosis by macrophages in MPS. ${ }^{59}$ Overexpression of antiphagocytic factors on exosomes, such as CD47, protects exosomes from MPS-mediated clearance, thereby significantly increasing their circulation time of exosomes by 3 -fold. ${ }^{75}$ Stealth strategies, such as surface PEGylation, also reduce the clearance of exosomes ${ }^{76,77}$ with the tradeoff of potential immunogenicity. ${ }^{78}$ In some cases, the reduced clearance resulted in improved tumor retention, which was attributed to passive accumulation of the PEGylated exosomes via EPR. ${ }^{76,77}$ In other cases, however, PEGylation of exosomes does not lead to increased tumor retention. ${ }^{79}$ Although tumoral blood vessels are commonly described as leaky and are compatible with extravasation of NPs, targeting surface molecules expressed on endothelial cells can potentiate tumor penetration. For example, one study showed that exosomes modified with iRGD (CRGDKGPDC) bind specifically to $\alpha_{\mathrm{v}}$ integrin which is highly expressed on endothelial cells of tumoral vessels, ${ }^{80}$ leading to an increased tumoral accumulation in breast cancer cell xenografted mice. ${ }^{29}$

\section{Active Tumor Targeting}

The downside of passive tumor targeting is the lack of ligand-selective binding for specific tissues or organs. In addition, once exosomes are distributed to the desired tissue or organ, manipulation of exosomes to increase cell-specific uptake is another challenge. In this section, various approaches to augment active tumor targeting of exosomes are reviewed from two aspects, including TME normalization and selective uptake by cancer cells (Table 2). These approaches aim to overcome sequential hurdles for efficient tumor targeted delivery. ${ }^{81}$

\section{Tumor Microenvironment Normalization}

The pathophysiology of TME is regulated by angiogenesis, fibrotic signaling, and hypoxia, which limit the intratumor infiltration of NPs following extravasation. ${ }^{82}$ In TME with an inflamed immune phenotype, the cancer-immunity cycle of antitumor immune response is disrupted partly due to $\mathrm{T}$ cell exhaustion. ${ }^{83} \mathrm{~A}$ novel application is to display synthetic bispecific antibodies on exosomal membranes. For example, one study utilized anti-EGFR scFv, which targets cancer cells, and anti-CD3 scFv, which redirects and activates cytotoxic T cells. ${ }^{84}$ The bispecific antibodies were displayed on exosomal membranes by fusing $\mathrm{scFv}$ antibodies with human platelet-derived growth factor receptor (PDGFR) transmembrane domain (TMD). The dual targeted exosomes normalized the immunosuppressed TME 


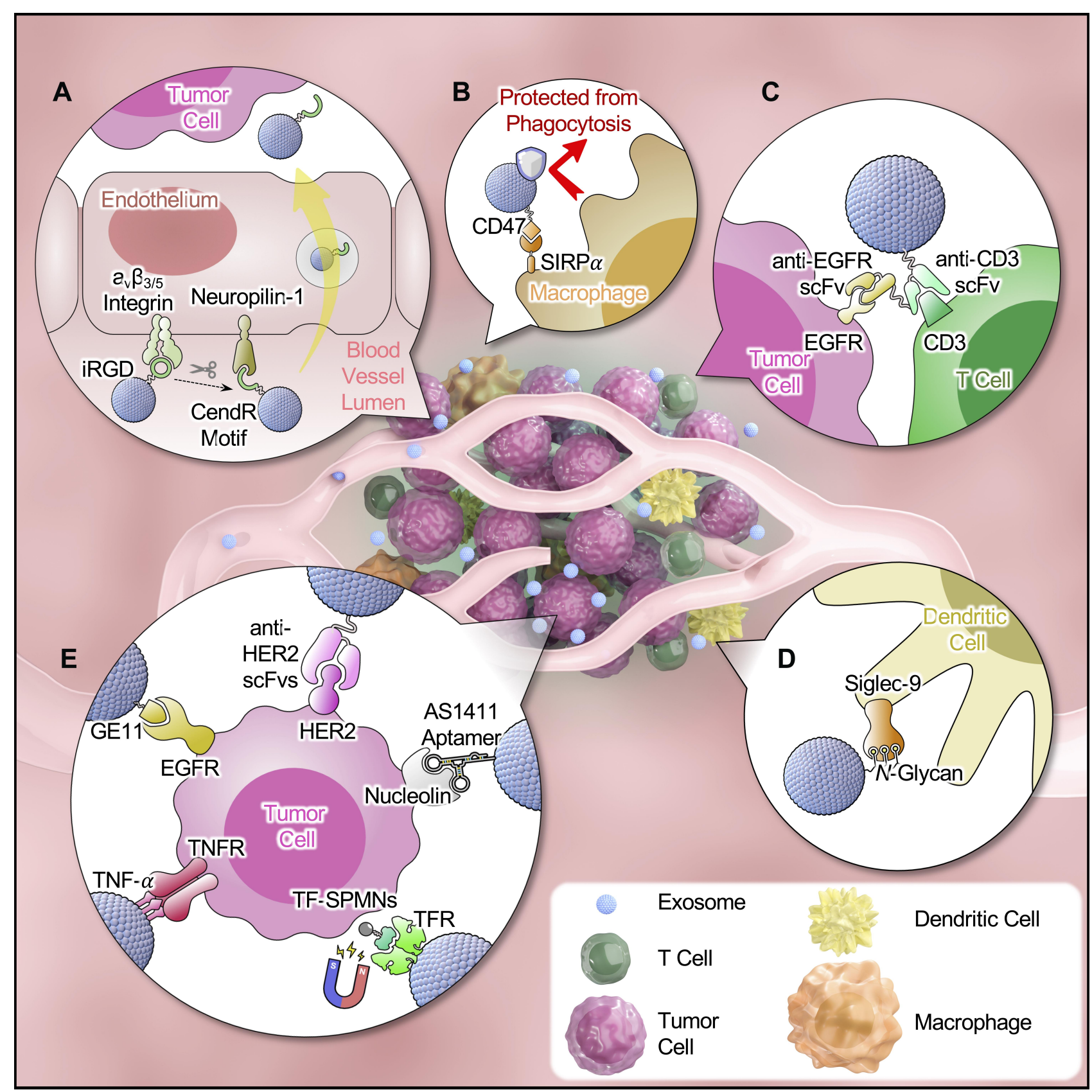

Figure I Graphical illustration of tumor targeting strategies of exosome-based delivery. In passive targeting, exosomes pass through the leaky vascular walls and accumulate at the tumor site by the enhanced permeability and retention (EPR) effect. The EPR effect is boosted by (A) increasing endothelial penetration of tumor vasculature by surface modification of iRGD peptide; ${ }^{80}$ and (B) prolonging circulation time of exosomes by overexpressing antiphagocytic factors. ${ }^{17}$ In addition, reshaping tumor microenvironment (TME) by targeting specific immune cells could enhance anti-tumor immune responses for cancer immunotherapy. For example, (C) exosome expressing in-tandem scFvs (anti-EGFR and anti-CD3) redirect cytotoxic T cells to attack tumor cells; ${ }^{84}$ and (D) glycan-modified exosomes displayed increased uptake by DC cells and augment DC-mediated immune responses. ${ }^{86}$ Active targeting can be achieved (E) by using specific targeting moiety to bind to the receptors on tumor cells or by modification to synergize external stimuli-guided tumor targeting. $93,95,101,102,105$.

by facilitating cancer recognition by $\mathrm{T}$ cells, a principle similar to bispecific $\mathrm{T}$ cell engagers (BiTEs). ${ }^{85}$ Compared with free bispecific antibodies, exosomes with genetically displayed antibody molecules showed significantly increased antibody avidity and more potent cytotoxicity in vitro. ${ }^{13}$ Another approach is to boost dendritic cell (DC)-mediated immune activation by glycan modification on exosomes. For example, glioblastoma-derived exosomes after de-sialylation and insertion of Lewis antigen, which contains fucosylated structures bound to DC-specific adhesion molecule CD209, resulted in a 4-fold increase of DC uptake and serves 
Table 2 Targeting Ligands Used in Preclinical Studies for Tumor Targeting

\begin{tabular}{|c|c|c|c|c|c|c|c|}
\hline Ligand Type & Examples & Effect & Parent Cell & Payload $^{\mathbf{a}}$ & $\begin{array}{l}\text { Preparation } \\
\text { Method }^{\mathbf{b}}\end{array}$ & $\begin{array}{l}\text { Size }^{c} \\
(\mathrm{~nm})\end{array}$ & Ref. \\
\hline \multirow[t]{4}{*}{ Antibody and fragments } & anti-SSTR2 mAb & $\begin{array}{l}\text { target somatostatin receptor } 2 \text { - } \\
\text { overexpressed neuroendocrine cancer }\end{array}$ & HEK293 cell & Rom & UF & 125 & 131 \\
\hline & $\begin{array}{l}\text { anti-EGFR } \\
\text { nanobodies }\end{array}$ & target cancer cells overexpressing EGFR & Neuro2A cells & NA & UF and SEC & 100 & 98 \\
\hline & $\begin{array}{l}\text { in-tandem scFvs } \\
\text { against CD3 and } \\
\text { HER2 }\end{array}$ & $\begin{array}{l}\text { redirect and activate cytotoxic } T \text { cells to } \\
\text { attack HER2-expressing breast cancer } \\
\text { cells }\end{array}$ & Expi293 cells & NA & UC & 109 & 13 \\
\hline & $\begin{array}{l}\text { anti-EGFR CAR, } \\
\text { anti-HER2 CAR }\end{array}$ & $\begin{array}{l}\text { exosomes containing cytotoxic molecules } \\
\text { and inhibit tumor growth }\end{array}$ & $\begin{array}{l}\text { effector CAR- } \\
T \text { cells }\end{array}$ & NA & UC and IMS & 85 & 46 \\
\hline \multirow[t]{3}{*}{ Proteins or ligands } & ITG $\beta 4$ & $\begin{array}{l}\text { suppress lung cancer cell proliferation and } \\
\text { migration }\end{array}$ & $\begin{array}{l}\text { MDA-MB-23I } \\
\text { cells }\end{array}$ & $\begin{array}{l}\text { miRNA- } \\
126\end{array}$ & $\begin{array}{l}\text { PureExo }{ }^{\circledR} \text { exosome } \\
\text { isolationKit }\end{array}$ & $\begin{array}{l}30- \\
120\end{array}$ & 132 \\
\hline & IL3 & $\begin{array}{l}\text { sensitize IL-3R-expressing CML cells to } \\
\text { imatinib }\end{array}$ & HEK293T cells & $\begin{array}{l}\text { BCR-ABL } \\
\text { siRNA }\end{array}$ & UC & $\begin{array}{l}30- \\
60\end{array}$ & 40 \\
\hline & biotin and avidin & target cancer cells overexpressing lectins & HUVECS & Dox & $\begin{array}{l}\text { microfluidic chip } \\
\text { with IC }\end{array}$ & $<150$ & 133 \\
\hline \multirow[t]{2}{*}{ Peptides } & GEII peptide & target EGFR-overexpressing cancer cells & HEK293 cells & miRNA & UC & 100 & 93 \\
\hline & $\begin{array}{l}\text { R8 peptide, } \\
\text { K4 peptide }\end{array}$ & stimulate tumor cell uptake of exosomes & HeLa cells & saporin & UC & $\begin{array}{l}160 \\
197\end{array}$ & $\begin{array}{l}134, \\
106\end{array}$ \\
\hline \multirow[t]{2}{*}{$\begin{array}{l}\text { Nucleic acid-based } \\
\text { ligands }\end{array}$} & ASI4II aptamer & $\begin{array}{l}\text { target tumor cells overexpressing } \\
\text { nucleolin }\end{array}$ & $\begin{array}{l}\text { MDA-MB-23I } \\
\text { cells }\end{array}$ & NA & $\begin{array}{l}\text { microfluidic } \\
\text { sonication }\end{array}$ & 181 & 101 \\
\hline & Sgc8 aptamer & $\begin{array}{l}\text { target protein tyrosine kinase } 7 \text {-positive } \\
\text { cancer cells }\end{array}$ & imDCs & Dox & UC & 111 & 135 \\
\hline \multirow[t]{2}{*}{ Small molecules } & Folic acid & bind folate receptors on cancer cells & milk exosome & $\begin{array}{l}\text { PTX, } \\
\text { DTX }\end{array}$ & UC & $\begin{array}{l}40- \\
100\end{array}$ & 136 \\
\hline & Sialic acid & bind lectin receptors on HeLa cells & MSCs & NA & UC & 178 & 137 \\
\hline
\end{tabular}

Notes: ${ }^{2}$ The abbreviations in the column of Payload stands for romidepsin (Rom), doxorubicin (Dox), paclitaxel (PTX) and docetaxel (DTX). ${ }^{b}$ The abbreviations in the column of Preparation method stands for ultrafiltration (UF), ultracentrifugation (UC), and size-exclusion chromatography (SEC), immunomagnetic separation (IMS) and immunocapture (IC). 'The sizes of exosomes were determined using either DLS (dynamic light scattering) or NTA (nanoparticle tracking analysis). The mean values of exosome diameters or size ranges were cited wherever one was reported.

as a potential anticancer vaccine. ${ }^{86}$ Since TME normalization using exosomes is still an emerging field, strategies utilized by other NPs that either depend on the physiochemical characteristics (eg, redox pressure, $\mathrm{pH}$ ) or on targeting specific cell populations in TME could be leveraged by exosomes. For instance, NPs modified with $\alpha$-peptide and M2 pep fusion peptide exhibited preferential delivery to M2 TAM over tissue resident macrophages by binding to scavenger receptor $B$ type 1 (SR-B1) on M2 macrophages. ${ }^{87}$ Surface conjugation of methotrexate as both a ligand and a toxin on NPs enables targeting and depletion of ovarian TAMs with high expression of folate receptor- $2 .^{88}$

\section{Cancer Cell Selectivity}

The primary cell type responsible for exosome uptake after tissue distribution may vary depending on organ as well as the origin of exosomes. For example, IV infused cholangiocyte-derived exosomes are preferentially taken up by hepatic stellate cells (HSCs) and HSC-derived fibroblasts in mouse liver. ${ }^{89}$ Kupffer cells (KCs) take up the bulk part of exosomes released by pancreatic ductal adenocarcinomas (PDACs). ${ }^{90}$ The underlying mechanisms of the cell type-specific targeting of exosomes remain to be elucidated. By nature, phosphatidylserine (PS) and carbohydrate moieties on exosomal membranes are involved in the recognition and uptake of exosomes by macrophages. 
For example, sialic acid on exosomes is recognized by CD169 on macrophages in vivo. ${ }^{91}$ This characteristic should therefore be considered in the design of targeted delivery systems, since exosomes taken up by macrophages such as KCs might be largely subject to hepatic clearance. One example is that surface modification of exosomes with cationized pullulan enhanced hepatocytespecific uptake of exosome by binding to asialoglycoprotein receptors on hepatocytes. As a result, the antiinflammatory effect of MSC-derived exosomes was potentiated in a concanavalin A-induced liver injury model. ${ }^{92}$ Moreover, a growing list of cell-targeting peptides, such as GE11 peptide targeting EGFR on solid tumor cells, ${ }^{93}$ and ischemic myocardium targeting peptide (IMTP) with unknown receptors to target ischemic myocardium, ${ }^{94}$ have been studied for use in modifying the exosomal surface. In addition, antibody or antibody fragments serve as versatile alternatives to active tumor targeting in exosomal surface modification. Compared with natural ligands or homing peptides, antibodies can be raised to target any antigens and, therefore, offer more freedom in target selection, in addition to an exquisite specificity due to higher binding affinity. The binding affinity of antibody or antibody fragments along with the target expression levels on cancer cell collectively determine the selectivity of exosomes. For example, high-affinity anti-Her2-scFv $\left(\mathrm{K}_{\mathrm{D}} \leq 1\right.$ $\mathrm{nM})$ and a high expression level of Her2 $\left(\geq 10^{6}\right.$ copies per cell) on cancer cells are optimally required to enable selective cell uptake of exosomes in Her2-positive cells. ${ }^{95}$

On a special note, the impact of fusion partners employed to display targeting moieties (peptide or antibody fragment) on the exosomal surface should not be neglected. There are many reports about the impact of membrane-inserted fusion proteins on the targeting effect of an exosome. For examples, membrane display by fusion with lysosomal associated membrane protein $2 b$ (Lamp2b) may cause ligand loss since it leads to peptide cleavage during exosome biogenesis. ${ }^{96}$ Lactadherin, a membraneassociated protein, ${ }^{97}$ and its peptide domains are located close to the membrane surface and not freely accessible to interact with cell receptors. Thus, incorporation of the C1C2 domain of lactadherin might interfere with cell uptake of exosomes. ${ }^{95}$ Furthermore, glycosylphosphatidylinositol (GPI) anchor signal peptides from decayaccelerating factor (DAF) renders an insufficient density of displayed ligands and, consequently, the increase of cell uptake of the modified exosomes is limited due to lack of receptor clustering to enable subsequent exosome internalization. $^{98}$

Chimeric antigen receptor $\mathrm{T}$ (CAR-T) cell-based immunotherapy has emerged as a promising new treatment with unprecedented results for hematological malignancies. ${ }^{99}$ Exosomes released from CAR-T cells also carry CAR on the exosomal surface. Interestingly, PD1 was not detected on CAR exosome surfaces compared with their parental cells. Therefore, CAR exosomes are compatible with recombinant PD-L1 immunotherapy without antagonizing the anti-tumor effects. ${ }^{46}$ Non-peptide targeting ligands, such as aptamers, have also been used to modify exosome surface. Aptamers are folded nucleic acid strands capable of binding to different target molecules with high programmability and low immunogenicity. ${ }^{100}$ In one study, cholesterol modified aptamer AS1411 conferred exosome enhanced tumor targeting in an MDA-MB -231-xenografted mouse model due to specific binding of AS1411 aptamers to nucleolin on breast cancer cells. ${ }^{101}$

Surface modification of exosomes also allows for 2-in1 or all-in-1 strategies to achieve tumor specific-killing. The synergistic tumor-killing effect has been demonstrated in the study of engineered Cas9 vector-encapsulated exosomes with the surface expression of tumor necrosis factor $(\mathrm{TNF} \alpha)$. In this case, $\mathrm{TNF} \alpha$ not only served as a targeting moiety to bind cancer cells overexpressing TNF receptors, but also triggered cancer cell necroptosis by activating TNF receptors. The downstream signaling pathways of $\mathrm{TNF} \alpha$ for survival or apoptosis are inactivated by cancerselective expression of Cas9. ${ }^{102}$ In addition, to take advantage of the intrinsic feature of cancer cells, exosomes have also been modified to synergize external stimuli-guided targeting, such as the encapsulation of sinoporphyrin sensitizer for focused ultrasound-guided delivery, ${ }^{103}$ or with conjugation with superparamagnetic nanoparticles (SPMNs) in external magnetic field-driven targeting. ${ }^{104,105}$

\section{Exosomes as Delivery Tools to Overcome Biological Barriers}

The antitumor effects of exosomes with therapeutic payloads also depend on the ability to deliver cargo to the intracellular action site (Figure 2). Approaches to enhance intracellular delivery for exosomes with encapsulated cargo are discussed, as the cell membrane is an existing barrier to the anti-tumor efficacy. ${ }^{81}$ In addition, the ability of exosomes to cross biological barriers, including the blood-brain barrier (BBB) and the gastrointestinal (GI) 


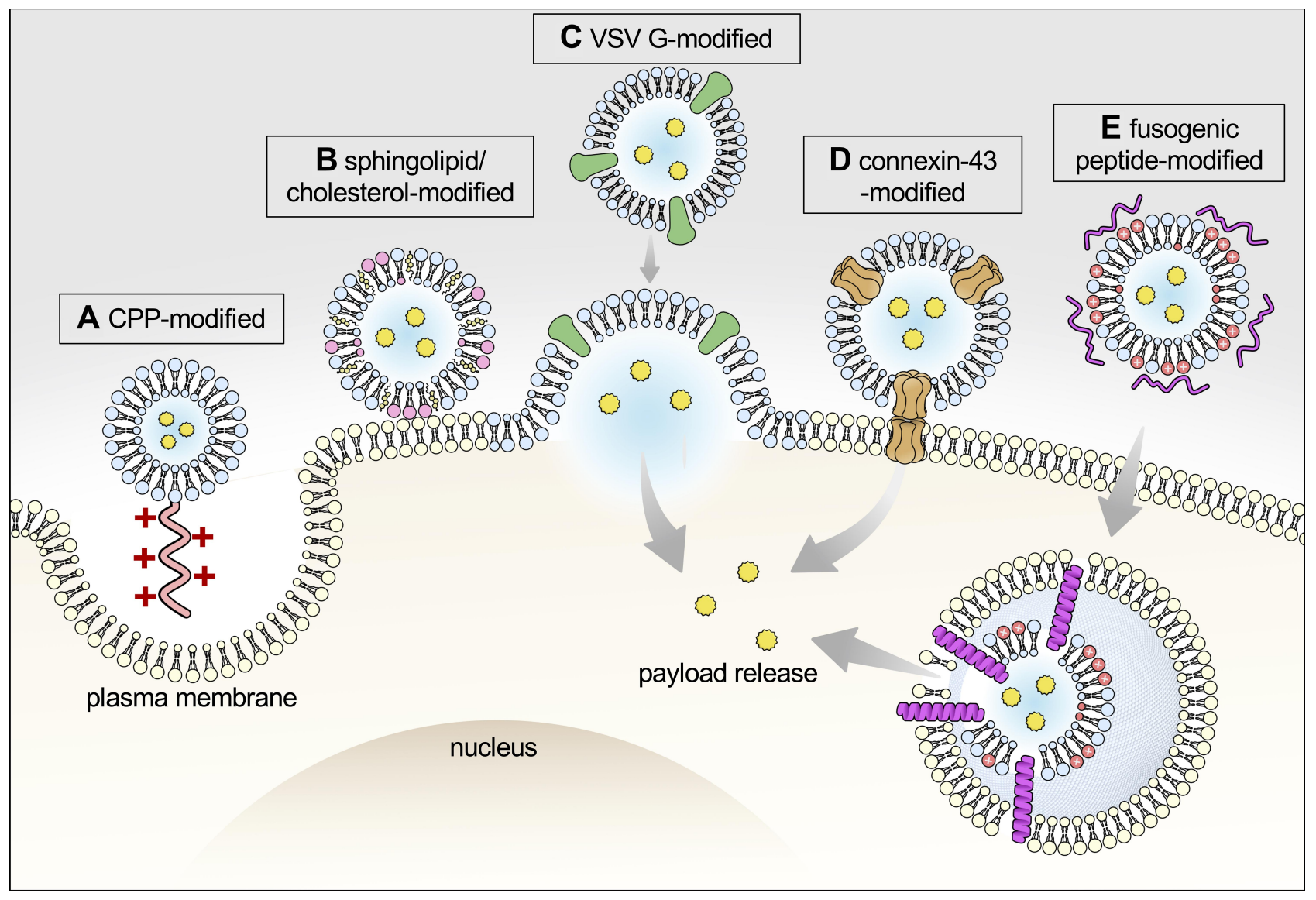

Figure 2 Graphical illustration of approaches to enhance intracellular payload delivery. Cell uptake of exosomes is mediated by several means, including endocytosis, phagocytosis, and direct fusion with plasma membrane. Intracellular payload delivery can be enhanced by several approaches, including: (A) modifying exosomes with cellpenetrating peptides (eg, arginine-rich peptide) to stimulate cell micropinocytosis; Promoting exosome-cell fusion by (B) increasing membrane rigidity of exosome via enriched sphingolipid and cholesterol; ${ }^{67}$ or by (C) expressing VSV-G on exosome to aid membrane fusion. ${ }^{107}$ (D) Exosomes expressing connexin-43 that forms hexametric channels to allow exosome to dock to gap junction pore on plasma membrane and, therefore, enable direct cytoplasmic transfer of cargo. ${ }^{108}$ In addition, (E) integrating fusogenic peptide (eg, GALA peptide) facilitates exosome escape of payload before lysosomal degradation. ${ }^{109}$

tract, inspire growing areas of research interests utilizing exosomes for drug delivery.

\section{Enhanced Intracellular Delivery}

Cells can take up exosomes by various means including direct membrane fusion, pinocytosis, and endocytosis. ${ }^{19}$ In order to facilitate exosome entry into cells, one approach is to equip exosomes with cell-penetrating peptide (CPPs), such as arginine-rich CPPs, which enhance exosome internalization by stimulating cell micropinocytosis. ${ }^{106}$ Another approach is by increasing the chance of membrane fusion. Biophysical studies suggest that increasing membrane rigidity by enriching sphingolipid and cholesterol improves fusion efficiency between exosomes and the recipient cells. ${ }^{67}$ In addition, exosomes with a surface display of $\mathrm{G}$ protein of vascular stomatitis virus (VSV-G) exhibit increased intracellular delivery of payloads by promoting exosome-cell membrane fusion. ${ }^{107}$ Integration of exosomes with connexin 43 (Cx43), a membrane protein that assembles to form hexametric channels, allows exosomes to dock at the gap junction pore embedded in the plasma membrane of recipient cells, and therefore provides another route for direct cytoplasmic transfer of exosome payload. ${ }^{108}$ As for internalized exosomes following the endosomal traffic route, the ability of the cargo to escape before lysosomal degradation is another challenge. Exosomes complexed with cationic lipids together with a pH-sensitive fusogenic peptide, GALA, increased exosome-endosome fusion and, therefore, aided in the cytosolic release of cargo. ${ }^{109}$ Currently, specific mechanisms for exosome internalization by cells remain to be elucidated. The inclusion of targeting moieties on exosomal membrane also impact the uptake of exosomes, as well as exosome distribution among cell organelles. For example, cell uptake of HEK293-derived naive exosomes is similar to the uptake of cholera toxin subunit B (CtxB), a marker for lipid raft-associated cell uptake. ${ }^{110}$ On the other hand, 
exosomes with a surface display of anti-Her2 $\mathrm{ScFv}$ increased overall cell uptake, with a greater extent of colocalization with transferrin and dextran, markers for clathrin-mediated endocytosis and micropinocytosis, respectively. ${ }^{95}$ The uptake mechanism also differs depending on recipient cells. The observed contributing fractions by caveolae-dependent endocytosis of exosomes vary among cell lines, which is partly subject to caveolin-1 expression levels. ${ }^{111}$ As the research community is starting to appreciate the diversity of exosomes in terms of size and originated cell organelles, trafficking routes other than the putative endosome destination, such as the nucleus, have also been described. ${ }^{112}$ Thus, exosomes may serve as potential tools to confer cell organelle-targeted delivery once the intracellular fates of exosomes are fully elucidated.

\section{BBB}

The BBB prevents the entry of toxic compounds into the brain and, consequently, restricts the delivery of most drugs for treatment of brain-associated diseases. Circulating exosomes are able to cross the BBB. Therefore, exosomes are considered as promising tools for drug delivery to the central nervous system (CNS) (Table 3). Exosomes derived from brain endothelial bEND. 3 cells are able to deliver anticancer drugs across the BBB in zebrafish embryos due to the homotypic effect of exosomes. ${ }^{113}$ Another study suggests that unmodified exosomes from macrophages are sufficient to confer BBB penetration in the context of brain inflammation, where the expression level of adhesion molecule 1
(ICAM-1) on endothelial cells increased the interaction with lymphocyte function-associated antigen 1 (LFA-1) on macrophages-derived exosome membranes. ${ }^{114}$ Exosomes modified with rabies viral glycoprotein (RVG) peptide, a CNS-specific peptide bound to acetylcholine receptor, also showed the ability to cross the BBB in vivo with minimal liver accumulation. ${ }^{115}$

\section{GI Tract}

Oral drug delivery is still a challenging task for many therapeutic biologics. Exosomes derived from milk or edible plants are able to cross intestinal barriers and, therefore, are considered as potential drug vectors for oral delivery. ${ }^{116,117}$ An interesting finding is the discrepancy of vector effect; milk exosomes were mainly distributed into the liver and spleen, whereas the encapsulated miRNA accumulated in the spleen and brain. The authors speculated that the distinct tissue distribution of payload was subject to a relayed substance transfer from foreign exosomes to endogenous exosomes in the endosomal traffic routes in cells, therefore allowing the cargo re-distribution to the brain. ${ }^{118}$

\section{Conclusion}

There are currently over 100 exosome-related clinical trials registered at Clinicaltrials.gov with projects spanning from early Phase I to Phase II. For trials to investigate exosomes as therapeutics (Table 4), the most commonly used producer cells are MSCs and immune cells with indications for neurodegenerative disease, inflammation, and cancers. MSC-

Table 3 Exosomes Displaying BBB Penetration

\begin{tabular}{|c|c|c|c|c|c|}
\hline Exosome Type & $\begin{array}{l}\text { Examples } \\
\text { (Approach or } \\
\text { Ligand/Target) }\end{array}$ & Parent Cell & Payload & Disease Model & Ref. \\
\hline \multirow[t]{3}{*}{ Naïve exosome } & \multirow{3}{*}{$\begin{array}{l}\text { intranasal } \\
\text { administration }\end{array}$} & EL-4 & curcumin & brain inflammation & 138 \\
\hline & & Raw 264.7 & caltase & Parkinson's disease & 139 \\
\hline & & Raw 264.7 & BDNF & LPS-induced brain inflammation & 114 \\
\hline \multirow{4}{*}{$\begin{array}{l}\text { Modified exosomes with } \\
\text { targeting peptide }\end{array}$} & \multirow{3}{*}{$\begin{array}{l}\text { RVG peptide/ } \\
\text { acetylcholine } \\
\text { receptor } \\
\text { cyclic RGD peptide/ } \\
\text { integrin } \alpha v \beta 3\end{array}$} & DCs & BACEI siRNA & Alzheimer's disease & 115 \\
\hline & & HEK 293 & $\begin{array}{l}\text { opioid receptor } \\
\text { Mu siRNA }\end{array}$ & Morphine relapse & 140 \\
\hline & & $\begin{array}{l}\text { mesenchymal } \\
\text { stromal cell }\end{array}$ & curcumin & $\begin{array}{l}\text { Cerebral ischemia /transient middle cerebral } \\
\text { artery occlusion (MCAO) mice }\end{array}$ & 141 \\
\hline & $\begin{array}{l}\text { RGE peptide/ } \\
\text { Neuropilin-I }\end{array}$ & Raw 264.7 & curcumin & orthotopic glioma models & 142 \\
\hline
\end{tabular}


Table 4 Exosomes in Clinical Trials

\begin{tabular}{|c|c|c|c|c|c|}
\hline Derived Sources & Payload & Indications & Phases & Sponsor & $\begin{array}{l}\text { ClinicalTrials.gov } \\
\text { Identifier }\end{array}$ \\
\hline $\begin{array}{l}\text { Allogenic adipose } \\
\text { MSCs }\end{array}$ & NA & $\begin{array}{l}\text { Severe COVID-19 } \\
\text { Pneumonia }\end{array}$ & Phase I & Ruijin Hospital & NCT04276987 \\
\hline Allogenic MSCs & miR-124 & Acute Ischemic Stroke & $\begin{array}{l}\text { Phase } \\
\mathrm{I} / 2\end{array}$ & Isfahan University of Medical Sciences & NCT03384433 \\
\hline $\begin{array}{l}\text { Adipose derived stem } \\
\text { cells }\end{array}$ & NA & Periodontitis & Phase I & Beni-Suef University & NCT04270006 \\
\hline Autologous plasma & NA & Cutaneous ulcers & Phase I & Kumamoto University & NCT02565264 \\
\hline Plant & curcumin & Colon Cancer & Phase I & University of Louisville & NCT0I 294072 \\
\hline $\begin{array}{l}\text { Allogenic COVID-19 } \\
\text { Specific T Cell }\end{array}$ & NA & Corona Virus Infection & Phase I & TC Erciyes University & NCT04389385 \\
\hline Umbilical MSCs & NA & Dry Eye & $\begin{array}{l}\text { Phase } \\
\mathrm{I} / 2\end{array}$ & Sun Yat-sen University & NCT042I3248 \\
\hline Umbilical MSCs & NA & Type I Diabetes Mellitus & Phase I & $\begin{array}{l}\text { General Committee of Teaching Hospitals } \\
\text { and Institutes, Egypt }\end{array}$ & NCT02I3833I \\
\hline MSCs & $\begin{array}{l}\text { KRAS GI 2D } \\
\text { SiRNA }\end{array}$ & $\begin{array}{l}\text { Metastatic Pancreatic } \\
\text { Adenocarcinoma }\end{array}$ & Phase I & M.D. Anderson Cancer Center & NCT0360863I \\
\hline MSCs & NA & Macular Holes & Phase I & Tianjin Medical University & NCT03437759 \\
\hline Grape & NA & Head and Neck Cancer & Phase I & University of Louisville & NCT0I668849 \\
\hline $\begin{array}{l}\text { Allogenic Adipose } \\
\text { MSCs }\end{array}$ & NA & Alzheimer's Disease & $\begin{array}{l}\text { Phase } \\
1 / 2\end{array}$ & Ruijin Hospital & NCT04388982 \\
\hline Allogenic MSCs & NA & $\begin{array}{l}\text { Dystrophic } \\
\text { Epidermolysis Bullosa }\end{array}$ & $\begin{array}{l}\text { Phase } \\
\mathrm{I} / 2\end{array}$ & Aegle Therapeutics & NCT04I73650 \\
\hline
\end{tabular}

Abbreviation: MSCs, mesenchymal stem cells.

derived exosomes with KRAS G12D siRNA for treating subjects with metastatic pancreas cancer is in phase I studies. Compared with liposomes, exosomes offer several unique advantages, including reduced immunogenicity, ${ }^{119}$ enhanced tissue penetration, ${ }^{120}$ and exosomes enable endogenous and site-specific cargo loading during exosome biogenesis. ${ }^{121}$ However, there are still challenges in exosome manufacturing, such as scaling-up the production yield and control of purity, especially considering the size overlap between exosomes and other extracellular vesicles (eg, microvesicles) or manufacture contamination (eg, lipoprotein aggregates). ${ }^{122}$ As for exosome-based targeted delivery, a comprehensive understanding of determinant attributes leading to selective-cell uptake of exosomes and factors influencing their intracellular disposition is still lacking. In addition, elucidation of mechanisms driving the homotypic tropism of exosomes, as well as to deciphering the relative contribution in exosome targeting when combining with the aforementioned targeting approaches, will bring great value for the rational design of exosome-based delivery tools. Lastly, extensive research is required to optimize the targeting of exosomes as signalosomes and drug delivery vehicles, as they will also resolve issues encountered by cell-based therapy, and may provide a path forward as an "all-in-one" cell-free therapeutic modality.

\section{Acknowledgments}

The authors would like to thank Professor Wei-Chiang Shen for his critical review and thank Dr. Yu-Sheng Chen for his help with graphic figures.

\section{Funding}

This work was funded by Advanced Projects of Innovation Program for the Selected Returned Overseas Chinese Scholars, Anhui Province (grant no. 2020LCX020) and Scientific Research Staring Foundation for Young 
Investigators, Anhui Medical University (grant no. XJ201920).

\section{Disclosure}

The authors report no conflicts of interest in this work.

\section{References}

1. Théry C, Witwer KW, Aikawa E, et al. Minimal information for studies of extracellular vesicles 2018 (MISEV2018): a position statement of the International Society for Extracellular Vesicles and update of the MISEV2014 guidelines. $J$ Extracellular Vesicles. 2018;7(1):1535750.

2. Théry C, Zitvogel L, Amigorena S. Exosomes: composition, biogenesis and function. Nat Rev Immunol. 2002;2(8):569-579. doi: $10.1038 /$ nri855

3. Van Niel G, d'Angelo G, Raposo G. Shedding light on the cell biology of extracellular vesicles. Nat Rev Mol Cell Biol. 2018;19 (4):213. doi:10.1038/nrm.2017.125

4. Johnstone RM, Adam M, Hammond J, Orr L, Turbide C. Vesicle formation during reticulocyte maturation. Association of plasma membrane activities with released vesicles (exosomes). $J$ Biol Chem. 1987;262(19):9412-9420.

5. Shao H, Im H, Castro CM, Breakefield X, Weissleder R, Lee H. New technologies for analysis of extracellular vesicles. Chem Rev. 2018;118(4):1917-1950. doi:10.1021/acs. chemrev.7b00534

6. Andaloussi SE, Mäger I, Breakefield XO, Wood MJ. Extracellular vesicles: biology and emerging therapeutic opportunities. Nat Rev Drug Discov. 2013;12(5):347-357. doi:10.1038/nrd3978

7. Kalluri R, LeBleu VS. The biology, function, and biomedical applications of exosomes. Science. 2020;367:6478. doi:10.1126/ science.aau6977

8. Crenshaw BJ, Gu L, Sims B, Matthews QL. Exosome biogenesis and biological function in response to viral infections. Open Virol J. 2018;12:134.

9. Zhou B, Xu K, Zheng X, et al. Application of exosomes as liquid biopsy in clinical diagnosis. Signal Transduction Targeted Therapy. 2020;5(1):1-14. doi:10.1038/s41392-020-00258-9

10. Syn NL, Wang L, Chow EK-H, Lim CT, Goh B-C. Exosomes in cancer nanomedicine and immunotherapy: prospects and challenges. Trends Biotechnol. 2017;35(7):665-676. doi:10.1016/j.tibtech.2017.03.004

11. Farooqi AA, Desai NN, Qureshi MZ, et al. Exosome biogenesis, bioactivities and functions as new delivery systems of natural compounds. Biotechnol Adv. 2018;36(1):328-334. doi:10.1016/j. biotechadv.2017.12.010

12. Maia J, Caja S, Strano Moraes MC, Couto N, Costa-Silva B. Exosome-based cell-cell communication in the tumor microenvironment. Frontiers Cell Developmental Biology. 2018;6:18. doi:10.3389/fcell.2018.00018

13. Shi X, Cheng Q, Hou T, et al. Genetically engineered cell-derived nanoparticles for targeted breast cancer immunotherapy. Mol Ther. 2020;28(2):536-547. doi:10.1016/j.ymthe.2019.11.020

14. Munoz JL, Bliss SA, Greco SJ, Ramkissoon SH, Ligon KL, Rameshwar P. Delivery of functional anti-miR-9 by mesenchymal stem cell-derived exosomes to glioblastoma multiforme cells conferred chemosensitivity. Molecular Therapy-Nucleic Acids. 2013;2:e126. doi:10.1038/mtna.2013.60

15. Lu M, Zhao X, Xing H, et al. Comparison of exosome-mimicking liposomes with conventional liposomes for intracellular delivery of siRNA. Int J Pharm. 2018;550(1-2):100-113. doi:10.1016/j. ijpharm.2018.08.040
16. Liao W, Du Y, Zhang C, et al. Exosomes: the next generation of endogenous nanomaterials for advanced drug delivery and therapy. Acta Biomater. 2019;86:1-14. doi:10.1016/j. actbio.2018.12.045

17. Kamerkar S, LeBleu VS, Sugimoto H, et al. Exosomes facilitate therapeutic targeting of oncogenic KRAS in pancreatic cancer. Nature. 2017;546(7659):498-503. doi:10.1038/nature22341

18. Gudbergsson JM, Jønsson K, Simonsen JB, Johnsen KB. Systematic review of targeted extracellular vesicles for drug delivery-considerations on methodological and biological heterogeneity. J Control Release. 2019;306:108-120. doi:10.1016/j. jconrel.2019.06.006

19. Pegtel DM, Gould SJ. Exosomes. Annu Rev Biochem. 2019;88:487-514. doi:10.1146/annurev-biochem-013118-111902

20. Shah R, Patel T, Freedman JE. Circulating extracellular vesicles in human disease. $N$ Engl $J$ Med. 2018;379(10):958-966. doi:10.1056/NEJMra1704286

21. Wan M, Ning B, Spiegel S, Lyon CJ, Hu TY. Tumor-derived exosomes (TDEs): how to avoid the sting in the tail. Med Res Rev. 2020;40(1):385-412. doi:10.1002/med.21623

22. Johnsen KB, Gudbergsson JM, Skov MN, Pilgaard L, Moos T, Duroux M. A comprehensive overview of exosomes as drug delivery vehicles - endogenous nanocarriers for targeted cancer therapy. Biochimica Et Biophysica Acta (BBA)-Reviews Cancer. 2014;1846(1):75-87. doi:10.1016/j.bbcan.2014.04.005

23. Bunggulawa EJ, Wang W, Yin T, et al. Recent advancements in the use of exosomes as drug delivery systems. J Nanobiotechnology. 2018;16(1):1-13. doi:10.1186/s12951-0180403-9

24. Balachandran B, Yuana Y. Extracellular vesicles-based drug delivery system for cancer treatment. Cogent Medicine. 2019;6 (1):1635806. doi:10.1080/2331205X.2019.1635806

25. Salunkhe S, Basak M, Chitkara D, Mittal A. Surface functionalization of exosomes for target-specific delivery and in vivo imaging \& tracking: strategies and significance. $J$ Control Release. 2020;326:599-614. doi:10.1016/j.jconrel.2020.07.042

26. Pérez-Bermúdez P, Blesa J, Soriano JM, Marcilla A. Extracellular vesicles in food: experimental evidence of their secretion in grape fruits. Eur $J$ Pharm Sci. 2017;98:40-50. doi:10.1016/j. ejps.2016.09.022

27. Kusuma RJ, Manca S, Friemel T, Sukreet S, Nguyen C, Zempleni J. Human vascular endothelial cells transport foreign exosomes from cow's milk by endocytosis. American J Physiology-Cell Physiology. 2016;310(10):C800-C807. doi:10.1152/ajpcell.00169.2015

28. Yang D, Zhang W, Zhang H, et al. Progress, opportunity, and perspective on exosome isolation-efforts for efficient exosome-based theranostics. Theranostics. 2020;10(8):3684. doi: $10.7150 /$ thno. 41580

29. Tian Y, Li S, Song J, et al. A doxorubicin delivery platform using engineered natural membrane vesicle exosomes for targeted tumor therapy. Biomaterials. 2014;35(7):2383-2390. doi:10.1016/j.biomaterials.2013.11.083

30. Morelli AE, Thomson AW. Tolerogenic dendritic cells and the quest for transplant tolerance. Nat Rev Immunol. 2007;7 (8):610-621. doi:10.1038/nri2132

31. Pitt JM, André F, Amigorena S, et al. Dendritic cell-derived exosomes for cancer therapy. J Clin Invest. 2016;126 (4):1224-1232. doi:10.1172/JCI81137

32. Zhu L, Kalimuthu S, Gangadaran P, et al. Exosomes derived from natural killer cells exert therapeutic effect in melanoma. Theranostics. 2017;7(10):2732. doi:10.7150/thno.18752

33. Wu C-H, Li J, Li L, et al. Extracellular vesicles derived from natural killer cells use multiple cytotoxic proteins and killing mechanisms to target cancer cells. J Extracellular Vesicles. 2019;8(1):1588538. doi:10.1080/20013078.2019.1588538 
34. Timmers L, Lim SK, Hoefer IE, et al. Human mesenchymal stem cell-conditioned medium improves cardiac function following myocardial infarction. Stem Cell Res. 2011;6(3):206-214. doi:10.1016/j.scr.2011.01.001

35. Li L, Zhang Y, Mu J, et al. Transplantation of human mesenchymal stem cell-derived exosomes immobilized in an adhesive hydrogel for effective treatment of spinal cord injury. Nano Lett. 2020.

36. Mianehsaz E, Mirzaei HR, Mahjoubin-Tehran M, et al. Mesenchymal stem cell-derived exosomes: a new therapeutic approach to osteoarthritis? Stem Cell Res Ther. 2019;10(1):340.

37. Peng Y, Zhao J-L, Peng Z-Y, Xu W-F, Yu G-L. Exosomal miR-25-3p from mesenchymal stem cells alleviates myocardial infarction by targeting pro-apoptotic proteins and EZH2. Cell Death Dis. 2020;11(5):1-15.

38. Yeo RWY, Lai RC, Zhang B, et al. Mesenchymal stem cell: an efficient mass producer of exosomes for drug delivery. $A d v$ Drug Deliv Rev. 2013;65(3):336-341. doi:10.1016/j. addr.2012.07.001

39. Dumont J, Euwart D, Mei B, Estes S, Kshirsagar R. Human cell lines for biopharmaceutical manufacturing: history, status, and future perspectives. Crit Rev Biotechnol. 2016;36(6):1110-1122.

40. Bellavia D, Raimondo S, Calabrese G, et al. Interleukin 3- receptor targeted exosomes inhibit in vitro and in vivo Chronic Myelogenous Leukemia cell growth. Theranostics. 2017;7 (5):1333-1345. doi:10.7150/thno.17092

41. Zhu X, Badawi M, Pomeroy S, et al. Comprehensive toxicity and immunogenicity studies reveal minimal effects in mice following sustained dosing of extracellular vesicles derived from HEK293T cells. J Extracellular Vesicles. 2017;6(1):1324730. doi:10.1080/ 20013078.2017.1324730

42. Ostrowski M, Carmo NB, Krumeich S, et al. Rab27a and Rab27b control different steps of the exosome secretion pathway. Nat Cell Biol. 2010;12(1):19-30.

43. Kim SM, Yang Y, Oh SJ, Hong Y, Seo M, Jang M. Cancerderived exosomes as a delivery platform of CRISPR/Cas9 confer cancer cell tropism-dependent targeting. J Control Release. 2017;266:8-16. doi:10.1016/j.jconrel.2017.09.013

44. Smyth T, Kullberg M, Malik N, Smith-Jones P, Graner MW, Anchordoquy TJ. Biodistribution and delivery efficiency of unmodified tumor-derived exosomes. $J$ Control Release. 2015;199:145-155. doi:10.1016/j.jconrel.2014.12.013

45. Daassi D, Mahoney KM, Freeman GJ. The importance of exosomal PDL1 in tumour immune evasion. Nat Rev Immunol. 2020;1-7.

46. Fu W, Lei $\mathrm{C}$, Liu $\mathrm{S}$, et al. CAR exosomes derived from effector CAR-T cells have potent antitumour effects and low toxicity. Nat Commun. 2019;10(1):1-12.

47. Morishita M, Takahashi Y, Nishikawa M, Takakura Y. Pharmacokinetics of exosomes - an important factor for elucidating the biological roles of exosomes and for the development of exosome-based therapeutics. J Pharm Sci. 2017;106 (9):2265-2269. doi:10.1016/j.xphs.2017.02.030

48. Ferguson S, Kim S, Lee C, Deci M, Nguyen J. The phenotypic effects of exosomes secreted from distinct cellular sources: a comparative study based on miRNA composition. AAPS J. 2018;20(4):67. doi:10.1208/s12248-018-0227-4

49. Chiu YJ, Cai W, Shih YRV, Lian I, Lo YH. A single-cell assay for time lapse studies of exosome secretion and cell behaviors. Small. 2016;12(27):3658-3666. doi:10.1002/smll.201600725

50. Charoenviriyakul C, Takahashi Y, Morishita M, Matsumoto A, Nishikawa M, Takakura Y. Cell type-specific and common characteristics of exosomes derived from mouse cell lines: yield, physicochemical properties, and pharmacokinetics. Eur J Pharm Sci. 2017;96:316-322. doi:10.1016/j.ejps.2016.10.009
51. Wu J-Y, Ji A-L, Wang Z-X, et al. Exosome-Mimetic Nanovesicles from Hepatocytes promote hepatocyte proliferation in vitro and liver regeneration in vivo. Sci Rep. 2018;8(1):1-11.

52. Oh K, Kim SR, Kim D-K, et al. In vivo differentiation of therapeutic insulin-producing cells from bone marrow cells via extracellular vesicle-mimetic nanovesicles. ACS Nano. 2015;9 (12):11718-11727. doi:10.1021/acsnano.5b02997

53. Jang SC, Kim OY, Yoon CM, et al. Bioinspired exosome-mimetic nanovesicles for targeted delivery of chemotherapeutics to malignant tumors. ACS Nano. 2013;7(9):7698-7710. doi:10.1021/ $\mathrm{nn} 402232 \mathrm{~g}$

54. Skotland T, Hessvik NP, Sandvig K, Llorente A. Exosomal lipid composition and the role of ether lipids and phosphoinositides in exosome biology. J Lipid Res. 2019;60(1):9-18.

55. Liu X, Sun Y, Xu S, et al. Homotypic cell membrane-cloaked biomimetic nanocarrier for the targeted chemotherapy of hepatocellular carcinoma. Theranostics. 2019;9(20):5828. doi:10.7150/ thno.34837

56. Lin $\mathrm{Y}, \mathrm{Wu} \mathrm{J}, \mathrm{Gu} \mathrm{W}$, et al. Exosome-liposome hybrid nanoparticles deliver CRISPR/Cas9 system in MSCs. Advanced Science. 2018;5(4):1700611. doi:10.1002/advs.201700611

57. Armstrong JP, Stevens MM. Strategic design of extracellular vesicle drug delivery systems. Adv Drug Deliv Rev. 2018;130:12-16. doi:10.1016/j.addr.2018.06.017

58. Morishita M, Takahashi Y, Nishikawa M, et al. Quantitative analysis of tissue distribution of the B16BL6-derived exosomes using a streptavidin-lactadherin fusion protein and iodine-125-labeled biotin derivative after intravenous injection in mice. $J$ Pharm Sci. 2015;104(2):705-713. doi:10.1002/jps. 24251

59. Wan Z, Zhao L, Lu F, et al. Mononuclear phagocyte system blockade improves therapeutic exosome delivery to the myocardium. Theranostics. 2020;10(1):218. doi:10.7150/ thno.38198

60. Elsharkasy OM, Nordin JZ, Hagey DW, et al. Extracellular vesicles as drug delivery systems: why and how? Adv Drug Deliv Rev. 2020. doi:10.1016/j.addr.2020.04.004

61. Matsumoto A, Takahashi Y, Nishikawa M, et al. Role of phosphatidylserine-derived negative surface charges in the recognition and uptake of intravenously injected B16BL6-derived exosomes by macrophages. J Pharm Sci. 2017;106(1):168-175. doi:10.1016/j.xphs.2016.07.022

62. Clayton A, Harris CL, Court J, Mason MD, Morgan BP. Antigen-presenting cell exosomes are protected from complement-mediated lysis by expression of CD55 and CD59. Eur J Immunol. 2003;33(2):522-531. doi:10.1002/ immu.200310028

63. Wang Q-L, Zhuang X, Sriwastva MK, et al. Blood exosomes regulate the tissue distribution of grapefruit-derived nanovector via CD36 and IGFR1 pathways. Theranostics. 2018;8(18):4912. doi: $10.7150 /$ thno. 27608

64. Blanco E, Shen H, Ferrari M. Principles of nanoparticle design for overcoming biological barriers to drug delivery. Nat Biotechnol. 2015;33(9):941. doi:10.1038/nbt.3330

65. Hoshino A, Costa-Silva B, Shen T-L, et al. Tumour exosome integrins determine organotropic metastasis. Nature. 2015;527 (7578):329-335. doi:10.1038/nature15756

66. Berenguer J, Lagerweij T, Zhao XW, et al. Glycosylated extracellular vesicles released by glioblastoma cells are decorated by CCL18 allowing for cellular uptake via chemokine receptor CCR8. J Extracellular Vesicles. 2018;7(1):1446660. doi:10.1080/20013078.2018.1446660

67. Parolini I, Federici C, Raggi C, et al. Microenvironmental $\mathrm{pH}$ is a key factor for exosome traffic in tumor cells. $J$ Biol Chem. 2009;284(49):34211-34222. doi:10.1074/jbc.M109.041152 
68. Saari H, Lázaro-Ibáñez E, Viitala T, Vuorimaa-Laukkanen E, Siljander P, Yliperttula M. Microvesicle-and exosome-mediated drug delivery enhances the cytotoxicity of Paclitaxel in autologous prostate cancer cells. J Control Release. 2015;220:727-737. doi:10.1016/j.jconrel.2015.09.031

69. Qiao L, Hu S, Huang K, et al. Tumor cell-derived exosomes home to their cells of origin and can be used as Trojan horses to deliver cancer drugs. Theranostics. 2020;10(8):3474. doi:10.7150/ thno. 39434

70. Watson DC, Bayik D, Srivatsan A, et al. Efficient production and enhanced tumor delivery of engineered extracellular vesicles. Biomaterials. 2016;105:195-205. doi:10.1016/j.biomaterials.20 16.07.003

71. Rosenblum D, Joshi N, Tao W, Karp JM, Peer D. Progress and challenges towards targeted delivery of cancer therapeutics. Nat Commun. 2018;9(1):1-12. doi:10.1038/s41467-018-03705-y

72. Chauhan VP, Jain RK. Strategies for advancing cancer nanomedicine. Nat Mater. 2013;12(11):958. doi:10.1038/ nmat3792

73. Kirpotin DB, Drummond DC, Shao Y, et al. Antibody targeting of long-circulating lipidic nanoparticles does not increase tumor localization but does increase internalization in animal models. Cancer Res. 2006;66(13):6732-6740. doi:10.1158/0008-5472. CAN-05-4199

74. Ojha T, Pathak V, Shi Y, et al. Pharmacological and physical vessel modulation strategies to improve EPR-mediated drug targeting to tumors. Adv Drug Deliv Rev. 2017;119:44-60. doi:10.1016/j.addr.2017.07.007

75. Yang Z, Shi J, Xie J, et al. Large-scale generation of functional mRNA-encapsulating exosomes via cellular nanoporation. Nature Biomedical Engineering. 2020;4(1):69-83. doi:10.1038/s41551019-0485-1

76. Shi S, Li T, Wen X, et al. Copper-64 labeled PEGylated exosomes for in vivo positron emission tomography and enhanced tumor retention. Bioconjug Chem. 2019;30(10):2675-2683. doi:10.1021/acs.bioconjchem.9b00587

77. Shi S, Wen X, Li T, Xiong C, Sood A. Radiolabeled pegylated exosomes for in vivo pet imaging and enhanced tumor retention. J Nucl Med. 2019;60(supplement 1):349.

78. d'Avanzo N, Celia C, Barone A, et al. Immunogenicity of polyethylene glycol based nanomedicines: mechanisms, clinical implications and systematic approach. Advanced Therapeutics. 2020;3 (3):1900170. doi:10.1002/adtp.201900170

79. Kooijmans S, Fliervoet L, Van Der Meel R, et al. PEGylated and targeted extracellular vesicles display enhanced cell specificity and circulation time. $J$ Control Release. 2016;224:77-85. doi:10.1016/j.jconrel.2016.01.009

80. Sugahara KN, Teesalu T, Karmali PP, et al. Tissue-penetrating delivery of compounds and nanoparticles into tumors. Cancer Cell. 2009;16(6):510-520. doi:10.1016/j.ccr.2009.10.013

81. Yong T, Wang D, Li X, et al. Extracellular vesicles for tumor targeting delivery based on five features principle. $J$ Control Release. 2020;322:555-565. doi:10.1016/j.jconrel.2020.03.039

82. Zhou Q, Dong C, Fan W, et al. Tumor extravasation and infiltration as barriers of nanomedicine for high efficacy: the current status and transcytosis strategy. Biomaterials. 2020;240:119902. doi:10.1016/j.biomaterials.2020.119902

83. Sharpe AH, Pauken KE. The diverse functions of the PD1 inhibitory pathway. Nat Rev Immunol. 2018;18(3):153. doi:10.1038/ nri.2017.108

84. Cheng Q, Shi X, Han M, Smbatyan G. Reprogramming exosomes as nanoscale controllers of cellular immunity. $\mathrm{J}$ Am Chem Soc. 2018;140(48):16413-16417. doi:10.1021/jacs.8b10047
85. Topp MS, Gökbuget N, Stein AS, et al. Safety and activity of blinatumomab for adult patients with relapsed or refractory B-precursor acute lymphoblastic leukaemia: a multicentre, single-arm, Phase 2 study. Lancet Oncol. 2015;16(1):57-66. doi:10.1016/S1470-2045(14)71170-2

86. Dusoswa SA, Horrevorts SK, Ambrosini M, et al. Glycan modification of glioblastoma-derived extracellular vesicles enhances receptor-mediated targeting of dendritic cells. J Extracellular Vesicles. 2019;8(1):1648995. doi:10.1080/ 20013078.2019.1648995

87. Qian Y, Qiao S, Dai Y, et al. Molecular-targeted immunotherapeutic strategy for melanoma via dual-targeting nanoparticles delivering small interfering RNA to tumor-associated macrophages. ACS Nano. 2017;11(9):9536-9549. doi:10.1021/ acsnano. $7 \mathrm{~b} 05465$

88. Penn CA, Yang K, Zong H, et al. Therapeutic impact of nanoparticle therapy targeting tumor-associated macrophages. Mol Cancer Ther. 2018;17(1):96-106. doi:10.1158/1535-7163.MCT17-0688

89. Liu R, Li X, Zhu W, et al. Cholangiocyte-derived exosomal long noncoding RNA H19 promotes hepatic stellate cell activation and cholestatic liver fibrosis. Hepatology. 2019;70(4):1317-1335. doi:10.1002/hep.30662

90. Costa-Silva B, Aiello NM, Ocean AJ, et al. Pancreatic cancer exosomes initiate pre-metastatic niche formation in the liver. Nat Cell Biol. 2015;17(6):816-826. doi:10.1038/ncb3169

91. Saunderson SC, Dunn AC, Crocker PR, McLellan AD. CD169 mediates the capture of exosomes in spleen and lymph node. Blood J American Society Hematology. 2014;123(2):208-216.

92. Tamura R, Uemoto S, Tabata Y. Augmented liver targeting of exosomes by surface modification with cationized pullulan. Acta Biomater. 2017;57:274-284. doi:10.1016/j.actbio.2017.05.013

93. Ohno S-I, Takanashi M, Sudo K, et al. Systemically injected exosomes targeted to EGFR deliver antitumor microRNA to breast cancer cells. Mol Ther. 2013;21(1):185-191. doi:10.1038/ mt.2012.180

94. Won Y-W, McGinn AN, Lee M, Bull DA, Kim SW. Targeted gene delivery to ischemic myocardium by homing peptide-guided polymeric carrier. Mol Pharm. 2013;10(1):378-385. doi:10.1021/ mp300500y

95. Longatti A, Schindler C, Collinson A, et al. High affinity single-chain variable fragments are specific and versatile targeting motifs for extracellular vesicles. Nanoscale. 2018;10 (29):14230-14244.

96. Hung ME, Leonard JN. Stabilization of exosome-targeting peptides via engineered glycosylation. J Biol Chem. 2015;290 (13):8166-8172. doi:10.1074/jbc.M114.621383

97. Véron P, Segura E, Sugano G, Amigorena S, Théry C. Accumulation of MFG-E8/lactadherin on exosomes from immature dendritic cells. Blood Cells Mol Dis. 2005;35(2):81-88. doi:10.1016/j.bcmd.2005.05.001

98. Kooijmans SA, Aleza CG, Roffler SR, van Solinge WW, Vader P, Schiffelers RM. Display of GPI-anchored anti-EGFR nanobodies on extracellular vesicles promotes tumour cell targeting. $J$ Extracellular Vesicles. 2016;5(1):31053. doi:10.3402/jev. v5.31053

99. Jackson HJ, Rafiq S, Brentjens RJ. Driving CAR T-cells forward. Nat Rev Clin Oncol. 2016;13(6):370-383. doi:10.1038/ nrclinonc. 2016.36

100. Thevendran R, Sarah S, Tang T-H, Citartan M. Strategies to bioengineer aptamer-driven nanovehicles as exceptional molecular tools for targeted therapeutics: A review. J Control Release. 2020 . 
101. Han Z, Lv W, Li Y, et al. Improving tumor targeting of exosomal membrane-coated polymeric nanoparticles by conjugation with aptamers. ACS Applied Bio Materials. 2020;3(5):2666-2673. doi:10.1021/acsabm.0c00181

102. Gulei D, Berindan-Neagoe I. Activation of necroptosis by engineered self tumor-derived exosomes loaded with CRISPR/Cas9. Molecular Therapy-Nucleic Acids. 2019;17:448-451.

103. Liu Y, Bai L, Guo K, et al. Focused ultrasound-augmented targeting delivery of nanosonosensitizers from homogenous exosomes for enhanced sonodynamic cancer therapy. Theranostics. 2019;9 (18):5261. doi:10.7150/thno.33183

104. Cao Y, Wu T, Zhang K, et al. Engineered exosome-mediated near-infrared-II region $\mathrm{V} 2 \mathrm{C}$ quantum dot delivery for nucleus-target low-temperature photothermal therapy. ACS Nano. 2019;13(2):1499-1510.

105. Qi H, Liu C, Long L, et al. Blood exosomes endowed with magnetic and targeting properties for cancer therapy. ACS Nano. 2016;10(3):3323-3333. doi:10.1021/acsnano.5b06939

106. Nakase I, Noguchi K, Fujii I, Futaki S. Vectorization of biomacromolecules into cells using extracellular vesicles with enhanced internalization induced by macropinocytosis. Sci Rep. 2016;6:34937. doi:10.1038/srep34937

107. Yang Y, Hong Y, Nam GH, Chung JH, Koh E, Kim IS. Virusmimetic fusogenic exosomes for direct delivery of integral membrane proteins to target cell membranes. Adv Mater. 2017;29 (13):1605604. doi:10.1002/adma.201605604

108. Lu M, Zhao X, Xing H, et al. Cell-free synthesis of connexin 43-integrated exosome-mimetic nanoparticles for siRNA delivery. Acta Biomater. 2019;96:517-536.

109. Nakase I, Futaki S. Combined treatment with a $\mathrm{pH}$-sensitive fusogenic peptide and cationic lipids achieves enhanced cytosolic delivery of exosomes. Sci Rep. 2015;5:10112. doi:10.1038/ srep 10112

110. Svensson KJ, Christianson HC, Wittrup A, et al. Exosome uptake depends on ERK1/2-heat shock protein 27 signaling and lipid Raft-mediated endocytosis negatively regulated by caveolin-1. $J$ Biol Chem. 2013;288(24):17713-17724. doi:10.1074/jbc. M112.445403

111. Horibe S, Tanahashi T, Kawauchi S, Murakami Y, Rikitake Y. Mechanism of recipient cell-dependent differences in exosome uptake. BMC Cancer. 2018;18(1):47. doi:10.1186/s12885-0173958-1

112. Santos MF, Rappa G, Karbanová J, Kurth T, Corbeil D, Lorico A. VAMP-associated protein-A and oxysterol-binding proteinrelated protein 3 promote the entry of late endosomes into the nucleoplasmic reticulum. $J$ Biol Chem. 2018;293 (36):13834-13848. doi:10.1074/jbc.RA118.003725

113. Yang T, Martin P, Fogarty B, et al. Exosome delivered anticancer drugs across the blood-brain barrier for brain cancer therapy in Danio rerio. Pharm Res. 2015;32(6):2003-2014. doi:10.1007/ s11095-014-1593-y

114. Yuan D, Zhao Y, Banks WA, et al. Macrophage exosomes as natural nanocarriers for protein delivery to inflamed brain. Biomaterials. 2017;142:1-12. doi:10.1016/j.biomaterials.20 17.07.011

115. Alvarez-Erviti L, Seow Y, Yin H, Betts C, Lakhal S, Wood MJ. Delivery of siRNA to the mouse brain by systemic injection of targeted exosomes. Nat Biotechnol. 2011;29(4):341-345. doi:10.1038/nbt.1807

116. Betker JL, Angle BM, Graner MW, Anchordoquy TJ. The potential of exosomes from cow milk for oral delivery. J Pharm Sci. 2019;108(4):1496-1505. doi:10.1016/j.xphs.2018.11.022

117. Zhang M, Viennois E, Xu C, Merlin D. Plant derived edible nanoparticles as a new therapeutic approach against diseases. Tissue Barriers. 2016;4(2):e1134415. doi:10.1080/ 21688370.2015 .1134415
118. Manca S, Upadhyaya B, Mutai E, et al. Milk exosomes are bioavailable and distinct microRNA cargos have unique tissue distribution patterns. Sci Rep. 2018;8(1):11321. doi:10.1038/ s41598-018-29780-1

119. Batrakova EV, Kim MS. Using exosomes, naturally-equipped nanocarriers, for drug delivery. $J$ Control Release. 2015;219:396-405. doi:10.1016/j.jconrel.2015.07.030

120. Wang Y, Yu D, Liu Z, et al. Exosomes from embryonic mesenchymal stem cells alleviate osteoarthritis through balancing synthesis and degradation of cartilage extracellular matrix. Stem Cell Res Ther. 2017;8(1):189. doi:10.1186/s13287-017-0632-0

121. Li SP, Lin ZX, Jiang XY, Yu XY. Exosomal cargo-loading and synthetic exosome-mimics as potential therapeutic tools. Acta Pharmacol Sin. 2018;39(4):542-551. doi:10.1038/aps.2017.178

122. Fais S, O'Driscoll L, Borras FE, et al. Evidence-based clinical use of nanoscale extracellular vesicles in nanomedicine. ACS Nano. 2016;10:3886-3899. doi:10.1021/acsnano.5b08015

123. Lamparski HG, Metha-Damani A, Yao J-Y, et al. Production and characterization of clinical grade exosomes derived from dendritic cells. J Immunol Methods. 2002;270(2):211-226. doi:10.1016/ S0022-1759(02)00330-7

124. Pang XL, Wang ZG, Liu L, et al. Immature dendritic cells derived exosomes promotes immune tolerance by regulating $\mathrm{T}$ cell differentiation in renal transplantation. Aging. 2019;11(20):8911-8924.

125. Wang G, Hu W, Chen H, Shou X, Ye T, Xu Y. Cocktail strategy based on nk cell-derived exosomes and their biomimetic nanoparticles for dual tumor therapy. Cancers. 2019;11(10):1560. doi:10.3390/cancers 11101560

126. Hoang DH, Nguyen TD, Nguyen H-P, et al. Differential wound healing capacity of mesenchymal stem cell-derived exosomes originated from bone marrow, adipose tissue and umbilical cord under serum-and xeno-free condition. Frontiers Molecular Biosciences. 2020;7.

127. Chen H-X, Liang F-C, Gu P, et al. Exosomes derived from mesenchymal stem cells repair a Parkinson's disease model by inducing autophagy. Cell Death Dis. 2020;11(4):1-17.

128. Sawada S-I, Sato YT, Kawasaki R, et al. Nanogel hybrid assembly for exosome intracellular delivery: effects on endocytosis and fusion by exosome surface polymer engineering. Biomaterials Science. 2020;8(2):619-630. doi:10.1039/C9BM01232J

129. Kalimuthu S, Gangadaran P, Rajendran RL, et al. A new approach for loading anticancer drugs into mesenchymal stem cell-derived exosome mimetics for cancer therapy. Front Pharmacol. 2018;9:1116.

130. Iravani S, Varma RS. Plant-derived edible nanoparticles and miRNAs: emerging frontier for therapeutics and targeted drug-delivery. ACS Sustain Chem Eng. 2019;7(9):8055-8069. doi:10.1021/acssuschemeng.9b00954

131. Si Y, Kim S, Zhang E, et al. Targeted exosomes for drug delivery: biomanufacturing, surface tagging, and validation. Biotechnol J. 2020;15(1):e1900163. doi:10.1002/biot.201900163

132. Nie H, Xie X, Zhang D, et al. Use of lung-specific exosomes for miRNA-126 delivery in non-small cell lung cancer. Nanoscale. 2020;12(2):877-887. doi:10.1039/C9NR09011H

133. Wang J, Li W, Zhang L, et al. Chemically edited exosomes with dual ligand purified by microfluidic device for active targeted drug delivery to tumor cells. ACS Appl Mater Interfaces. 2017;9 (33):27441-27452. doi:10.1021/acsami.7b06464

134. Nakase I, Ueno N, Katayama M, et al. Receptor clustering and activation by multivalent interaction through recognition peptides presented on exosomes. Chem Commun. 2016;53(2):317-320. doi:10.1039/C6CC06719K

135. Zou J, Shi M, Liu X, et al. Aptamer-functionalized exosomes: elucidating the cellular uptake mechanism and the potential for cancer-targeted chemotherapy. Anal Chem. 2019;91 (3):2425-2430. doi:10.1021/acs.analchem.8b05204 
136. Munagala R, Aqil F, Jeyabalan J, Gupta RC. Bovine milk-derived exosomes for drug delivery. Cancer Lett. 2016;371(1):48-61. doi:10.1016/j.canlet.2015.10.020

137. Shimoda A, Tahara Y, Sawada SI, Sasaki Y, Akiyoshi K. Glycan profiling analysis using evanescent-field fluorescence-assisted lectin array: importance of sugar recognition for cellular uptake of exosomes from mesenchymal stem cells. Biochem Biophys Res Commun. 2017;491(3):701-707. doi:10.1016/j.bbrc.2017.07.126

138. Zhuang X, Xiang X, Grizzle W, et al. Treatment of brain inflammatory diseases by delivering exosome encapsulated anti-inflammatory drugs from the nasal region to the brain. Mol Ther. 2011;19(10):1769-1779. doi:10.1038/mt.2011.164

139. Haney MJ, Klyachko NL, Zhao Y, et al. Exosomes as drug delivery vehicles for Parkinson's disease therapy. $J$ Control Release. 2015;207:18-30. doi:10.1016/j.jconrel.2015.03.033
140. Liu Y, Li D, Liu Z, et al. Targeted exosome-mediated delivery of opioid receptor $\mathrm{Mu}$ siRNA for the treatment of morphine relapse. Sci Rep. 2015;5:17543. doi:10.1038/srep17543

141. Tian T, Zhang HX, He CP, et al. Surface functionalized exosomes as targeted drug delivery vehicles for cerebral ischemia therapy. Biomaterials. 2018;150:137-149. doi:10.1016/j. biomaterials.2017.10.012

142. Jia G, Han Y, An Y, et al. NRP-1 targeted and cargo-loaded exosomes facilitate simultaneous imaging and therapy of glioma in vitro and in vivo. Biomaterials. 2018;178:302-316. doi:10.1016/j.biomaterials.2018.06.029

\section{Publish your work in this journal}

The International Journal of Nanomedicine is an international, peerreviewed journal focusing on the application of nanotechnology in diagnostics, therapeutics, and drug delivery systems throughout the biomedical field. This journal is indexed on PubMed Central, MedLine, CAS, SciSearch ${ }^{\mathbb{R}}$, Current Contents ${ }^{\mathbb{B}} /$ Clinical Medicine, $^{2}$
Journal Citation Reports/Science Edition, EMBase, Scopus and the Elsevier Bibliographic databases. The manuscript management system is completely online and includes a very quick and fair peer-review system, which is all easy to use. Visit http://www.dovepress.com/ testimonials.php to read real quotes from published authors. 